\title{
Release of Respirable Fibrous Dust from Carbon Fibers Due to Splitting along the Fiber Axis
}

\author{
Dominic Kehren*, Barbara Simonow, Daphne Bäger, Nico Dziurowitz, Daniela Wenzlaff, \\ Carmen Thim, Judith Neuhoff, Asmus Meyer-Plath, Sabine Plitzko
}

Federal Institute for Occupational Safety and Health (BAuA), Berlin 10317, Germany

\begin{abstract}
The aim of this report is to sensitize to the fact that some types of carbon fibers can split along the fiber axis during machining processes, thus becoming a source of respirable fibrous fragments in high concentrations. The risk of releasing respirable fiber dust must be assessed both in terms of carbon fiber materials and handling processes. We present an analysis of fiber concentrations released during mechanical processing of carbon fiber reinforced polymers at two different workplaces together with measurements from abrasion testing in a closed laboratory setup with inherent bulk sample analysis. During workplace measurements of the machining of polymer composites that were reinforced with pitch-based carbon fibers,

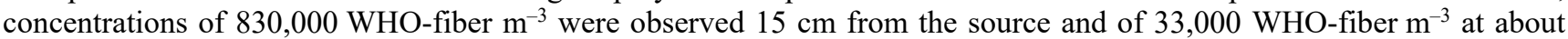
$3 \mathrm{~m}$ distance. An explanation for such a high release propensity for respirable fibers with diameters below $3 \mu \mathrm{m}$ is a fiber splitting along the axis of the studied fiber type. Comparative abrasion experiments of pitch and polyacrylonitrile-based carbon fiber reinforced polymer composites revealed that their fracture behavior differs from another. The studied polyacrylonitrile-based carbon fibers broke primarily perpendicular to their axis, whereas the studied pitch-based carbon fibers show fiber splicing and splitting along the fiber axis. In order to predict and manage health risks of the large variety of existing carbon fiber materials, the understanding of the relation between fiber microstructure, fracture morphology and WHO-fiber release propensity must be urgently improved. In the meantime, all handling and processing steps of pitchbased carbon fibers have to be accompanied by precautionary or exposure measurement-controlled safety measures to protect the employees.
\end{abstract}

Keywords: Carbon fiber reinforced polymers; Carbon fiber splitting; WHO-fibers; Occupational health; Mesophase pitch.

\section{INTRODUCTION}

Carbon fibers (CF) are known for their excellent mechanical, thermal and electrical properties. In a multitude of industrially relevant applications, for example in aerospace, automotive and wind energy sectors, a high and currently increasing demand for carbon fiber composites can be found. The global demand for carbon fiber reinforced polymers (CFRP) exceeded 130,000 tons in 2018, with an annual growth rate of around 11\% (Industry Experts, 2018). CFs can be categorized according to the precursor material. While polyacrylonitrile-based CF (panCF) have a market share of about $95 \%$, mesophase pitch-based CF (pitchCF) are mainly used in high value or niche applications that require specific material properties, promise high added value and allow for a higher material price, such as satellites

\footnotetext{
${ }^{*}$ Corresponding author.

Tel.: +49 30515484351

E-mail address: Kehren.dominic@baua.bund.de
}

or energy generation. These two types of CF generally tend to differ with respect to microstructure and material properties (Huang, 2009; Naito et al., 2017), with pitchCF generally exhibiting a higher thermal conductivity and lower elongation at break.

CF are typically fabricated with diameters of 7-10 $\mu \mathrm{m}$ and are accordingly considered non-respirable. The World Health Organization (WHO) considers fibers with a length $\geq 5 \mu \mathrm{m}$, a diameter $\leq 3 \mu \mathrm{m}$ and an aspect ratio $\geq 3$ as respirable and therefore exposure relevant (WHO-fibers) (WHO, 1997). The clearance of insoluble WHO-fibers that entered the alveoli in the deep airways by lung self-cleaning mechanisms is considered impeded for morphological reasons, which may render them long term biopersistent. Hence, they can become the cause of chronic inflammation and may increase the risk to develop mesothelioma (Donaldson et al., 2010). In previous studies, CF have shown little or no pathological effect (Holt and Horne, 1978; Warheit, 1994; Wang et al., 2017). One study described in Warheit (1994) and Warheit et al. (2001) observed a dose-dependent but only transient inflammatory response in the lungs of exposed rats following acute 
inhalation of pitchCF with diameters of $1-4 \mu \mathrm{m}$. This and other short-term inhalation studies have been criticized to be not suited to identify fiber-related risks (Gandhi et al., 1999; Rödelsperger, 2004).

However, from an occupational hygiene perspective and according to the fiber pathogenicity paradigm (Pott and Friedrichs, 1972; Stanton and Wrench, 1972), any handling of non-respirable biopersistent fibers must raise concerns whenever respirable fragments of these fibers or fibers that have been reduced below their original diameter could be released. Such release may result from application of mechanical or thermal stress during handling or processing (Eibl et al., 2014; Eibl, 2017), for example during recycling processes or after incomplete combustion/burning off of CFRP that may lead to CF thinning by surface burn-up. Inherently, it can be assumed that these processes can lead to changes in fiber integrity, fiber shape and fiber properties. Porous and brittle as well as thinned carbon fibers have been reported to result from thermal oxidation during fire or pyrolysis in the presence of residual oxygen (Gandhi et al., 1999; Eibl et al., 2014). Accordingly, alveolar fiber dusts can originate from all these abovementioned processes. In the context of a risk assessment for the handling of $\mathrm{CF}$, the risk of respirable fiber dust release cannot be ruled out in principle but must be studied both in terms of the materials used and processes applied.

Previous studies on fragment release from CFRP during machining describe generally no or only a low release of respirable particles (Henry et al., 1982; Gieseke et al., 1984; Wang et al., 2017). Schlagenhauf et al. (Schlagenhauf et al., 2015) found that during tensile testing of CFRP cables respirable fibers with diameters smaller than the original one were released. However, the concentration at the studied workplace was found to be below the permissible exposure limit (PEL) for WHO-fibers based on the "Recommendation from the Scientific Committee on Occupational Exposure Limits for manmade-mineral fibres (MMMF) with no indication for carcinogenicity and not specified elsewhere" (SCOEL/SUM/88, March 2012) which recommends a value of 1 fiber $\mathrm{cm}^{-3}$. Bello et al. (Bello et al., 2009; Bello et al., 2010) investigated the particle release during dry and wet cutting of composites containing CF and carbon nanotubes and found - among other objectsfiber fragments thinner than the initial fiber diameter of the used CF, thus implying a fracture along the fiber axis. Most of these studies, however, have been performed with panCF and their findings, as we will discuss in the following, must not transferred to similar processes using pitchCF.

Due to a lack of sound toxicological data CF are for the moment not yet regulated by a material specific occupational exposure limit (OEL). However, with regard to the fiber pathogenicity paradigm (Stanton and Wrench, 1972), inhalation of respirable biopersistent fibers must be associated with a potential health risk, including lung cancer and mesothelioma. This paradigm has even been reported to hold for nanoscale fibers (Donaldson et al., 2010). As a consequence, all bio durable fibrous materials or materials known to potentially emit fibrous objects are to be considered as potentially hazardous and are governed by material unspecific OELs like the one mentioned above (SCOEL/SUM/88, March 2012). According to the German "Technical Rules for Hazardous Substances" [TRGS 905] (AGS, 2016), in Germany all inorganic fiber dusts with WHO dimensions but insufficient toxicological data are subject to carcinogenicity class 2 of the European CLP Regulation ("Classification, Labelling and Packaging" (European Union, 2008)) and therefore are governed by an OEL of 50,000 WHO-fiber $\mathrm{m}^{-3}$. In comparison, the OEL for asbestos is 10,000 WHO-fiber $\mathrm{m}^{-3}$. We will take both values into account for the evaluation of our results below, precautionary assuming asbestos like behavior.

In this report we present and discuss two consecutive studies. First of all, results are shown for orienting or preliminary workplace exposure measurements that observed the release of respirable fiber dust from pitch-based $\mathrm{CF}$ reinforced polymer (pitchCFRP) during machining at a band saw and tensile testing at two different workplaces. Filter samples of the workplace atmosphere were collected on track-etched membrane filters and systematically evaluated by means of scanning electron microscopy (SEM). Imaged dust particles were morphologically characterized, and concentrations of respirable fibers were determined in close proximity to the emission source and in the far-field. Previously unreported, worryingly and surprisingly high workplace concentrations of potentially harmful fibers were found. This motivated the second part of our study, in which controlled abrasion experiments of the same pitchCFRP samples in comparison with PAN-based CF reinforced plastic (panCFRP) samples were performed in a laboratory abrasion test chamber with low particle background. Bulk samples of the airborne dust and of non-aerosolized abraded material were collected and used for subsequent dust morphology determination and fracture behavior interpretation.

\section{MATERIALS AND METHODS}

\section{Materials}

During workplace measurements, plates of pitchCFRP test specimens were used that consisted of epoxy resin and ultrahigh-modulus pitchCF with fiber diameters of approximately $10 \mu \mathrm{m}$, a Young's modulus of $640 \mathrm{GPa}$, an elongation at break of $0.4 \%$ and a density of $2.1 \mathrm{~g} \mathrm{~cm}^{-3}$.

Thread packages, tubular coiled CF, were used for the abrasion experiments. They were composed of epoxy resin and either pitchCF or panCF. The pitchCFRP thread package was made of the same resin and pitchCF that were previously used for the specimen in the workplace measurements. The panCFRP thread package was made of the same resin and panCF with a fiber diameter of approximately $7 \mu \mathrm{m}$, a Young's modulus of $230 \mathrm{GPa}$, an elongation at break of $2.1 \%$ and a density of $1.8 \mathrm{~g} \mathrm{~cm}^{-3}$.

\section{Strategy for the Workplace Measurement}

The workplace measurements were performed in close accordance with established strategies for measuring airborne fibers, in particular the German Standard VDI 3492 "Measurement of inorganic fibrous particles - Scanning 
electron microscopy method" (VDI, 2013) and the recommendations given by the WHO "Determination of airborne fibre number concentrations" (WHO, 1997). In both strategies, samples are to be collected by drawing a known volume of air through a membrane filter, which is used to determine the concentration of airborne fibers by correlating the number of counted fibers to the corresponding air volume of the analyzed filter area.

The measurements aimed at clarifying whether and to what extent, under the conditions examined, respirable fragments of pitch-based CF are released. Due to previous reports of only insignificant emissions in the literature, samples were taken as close to the emission source as possible. The near-field (NF) measurements were complemented by far-field (FF) measurements at a distance of approximately $3 \mathrm{~m}$ from the emission source. Prior to, during and after mechanical composite stressing by sawing and tensile testing, the particle number concentration was monitored at a distance of approximately $1 \mathrm{~m}$ from the emission source with a condensation particle counter (CPC, model 5.403, Grimm Aerosol GmbH, Ainring, Germany; measuring range $4.5 \mathrm{~nm}$ to $>3 \mu \mathrm{m}$ ) and an optical particle counter (OPC, model 1.109, Grimm Aerosol GmbH, Ainring, Germany; measuring range $200 \mathrm{~nm}$ to $>20 \mu \mathrm{m}$ ). These two devices have been used for all CPC or OPC measurements carried out in this study. These kinds of measurement devices represent a fast and simple way to assess the particle number concentrations at workplaces. Their efficiency and reliability for fibers, however, still needs to be studied and reviewed.

Gold-coated track-etched membrane filters $(200 \mathrm{~nm}$ nominal pore diameter, $25 \mathrm{~mm}$ filter diameter, APC GmbH, Eschborn, Germany) were used for the collection of bulk air samples of the workplace atmosphere. Each filter was mounted in an open-faced filter holder (asbestos cassette,
SKC Inc., Eighty Four, PA, USA), which was connected to a pulsation-free, flow-calibrated vacuum pump. Due to the limited duration of the monitored work task of about 90 min including cleaning, the sampling duration was set to approximately $90 \mathrm{~min}$ including $30 \mathrm{~min}$ decay time of the concentration after processing. Further sampling details and results are given in Table 1 .

To determine the concentration of airborne fibers, the filters were analyzed by SEM, as described in detail in section "SEM analysis of bulk samples". All fibers and agglomerates with a minimum length of $5 \mu \mathrm{m}$, a maximum diameter of $3 \mu \mathrm{m}$ and an aspect ratio $\geq 3$ were counted. In order to also take the nanoscale fraction into account, deviating from the measurement strategies mentioned before, the lower evaluation limits of countable WHO-fiber diameters were reduced from $200 \mathrm{~nm}$ to $20 \mathrm{~nm}$, as described in a recently proposed measurement strategy (Plitzko et al., $2018 \mathrm{a}, \mathrm{b})$. For low concentration samples, the lower limit of detection was adjusted to reach less than 10,000 WHOfiber $\mathrm{m}^{-3}$ by analyzing a filter area corresponding to an air volume of at least $0.3 \mathrm{~L}$. 10,000 WHO-fiber $\mathrm{m}^{-3}$ conforms an occupational exposure limit for a risk level of $4 \cdot 10^{-4}$ for asbestos and comparably hazardous fiber substances. Additionally to the fiber concentrations reported here lower and upper interval limits of the $95 \%$ confidence interval according to Poisson statistics have been calculated.

Please note that due to the process-related sampling at high air flow rates close to the emission source, the SEM analysis of bulk air samples delivered process-related fiber number concentrations, which may not be comparable with fiber-concentration limit values defined for 4 hour or 8 hour reference working periods (shifts).

\section{Workplaces}

The orienting workplace measurements were carried out

Table 1. Sampling parameter and details to SEM image analysis. The samples were taken during or before sawing and tensile testing of pitchCFRP material at workplace.

\begin{tabular}{|c|c|c|c|c|c|c|c|c|c|}
\hline \multirow[t]{2}{*}{ Sample } & \multirow{2}{*}{$\begin{array}{l}\text { Sampling } \\
\text { flow } \\
{\left[\mathrm{L} \mathrm{min}^{-1}\right]}\end{array}$} & \multirow{2}{*}{$\begin{array}{l}\text { Sampling } \\
\text { time } \\
{[\mathrm{min}]}\end{array}$} & \multirow{2}{*}{$\begin{array}{l}\text { Distance } \\
\text { to ES } \\
{[\mathrm{m}]}\end{array}$} & \multirow{2}{*}{$\begin{array}{l}\text { Number } \\
\text { of images }^{1}\end{array}$} & \multirow{2}{*}{$\begin{array}{l}\text { Analyzed } \\
\mathrm{FA}^{2} \\
{\left[\mathrm{~mm}^{2}\right]}\end{array}$} & \multirow{2}{*}{$\begin{array}{l}\text { WHO } \\
\text { objects } \\
\text { found }^{3}\end{array}$} & \multirow{2}{*}{$\begin{array}{l}\text { WHO fiber } \\
\text { concentration } \\
{\left[\mathrm{m}^{-3}\right]}\end{array}$} & \multicolumn{2}{|c|}{$\begin{array}{l}95 \% \text { confidence limits for } \\
\text { WHO fiber concentration }\end{array}$} \\
\hline & & & & & & & & Lower $\left[\mathrm{m}^{-3}\right]$ & Upper $\left[\mathrm{m}^{-3}\right]$ \\
\hline Sawing NF & 5 & 87 & 0.15 & 50 & $\begin{array}{l}0.151 \\
(0.17 \mathrm{~L})\end{array}$ & $116(+28)$ & 832,519 & 702,099 & 980,137 \\
\hline Sawing FF & 8 & 94 & 2.5 & 50 & $\begin{array}{l}0.151 \\
(0.30 \mathrm{~L})\end{array}$ & $6.5(+3.5)$ & 33,372 & 16,003 & 61,372 \\
\hline Sawing BG & 5 & 963 & - & 28 & $\begin{array}{l}0.085 \\
(1.07 \mathrm{~L})\end{array}$ & 0 & 0 & 0 & 2,794 \\
\hline Tensile test NF & 5 & 93 & 0.10 & 50 & $\begin{array}{l}0.151 \\
(0.18 \mathrm{~L})\end{array}$ & $46.5(+32)$ & 424,558 & 335,863 & 529,495 \\
\hline Tensile test FF & 8 & 90 & 3 & 72 & $\begin{array}{l}0.218 \\
(0.41 \mathrm{~L})\end{array}$ & 0 & 0 & 0 & 7,267 \\
\hline Tensile test BG & 5 & 1010 & - & 20 & $\begin{array}{l}0.060 \\
(0.81 \mathrm{~L})\end{array}$ & 0 & 0 & 0 & 3,708 \\
\hline
\end{tabular}

(NF: near-field; FF: far-field; BG: background; ES: emission source; FA: filter area)

${ }^{1}$ Each image was record at a magnification of $\times 2000$ with a standard resolution of $5120 \times 3840$ pixels $(12.4 \mathrm{~nm} / \mathrm{pixel})$.

${ }^{2}$ By taking the total filter area and sample volume into account, the analyzed filter area can be correlated to the volume given in brackets.

${ }^{3}$ The first value is the number of WHO fiber, the second value in brackets is the number of WHO agglomerates. Both values were taking into account for the calculation of the WHO fiber concentration. 
at the technical center of a research facility, in which two mechanical processing steps of the same pitchCFRP material were investigated.

In the first work process, plates of the pitchCFRP material were cut into strips on a band saw (HEMA SR500, Herrmann Maschinenbau $\mathrm{GmbH}$ ). The dry cutting saw was operated with a diamond saw blade and local exhaust ventilation $\left(1.2 \mathrm{~m} \mathrm{~s}^{-1}\right.$, filter unit class $\left.\mathrm{F}\right)$ above the workpiece. The band saw was located inside a large machine hall (approx. 2,400 $\mathrm{m}^{3}$ ) and was surrounded by walls for visual protection (L: $9.0 \mathrm{~m}$; B: $2.6 \mathrm{~m}$; H: $2.4 \mathrm{~m}$ ), upwards opened to the hall. There was no ventilation in the hall and during the measurements the windows and doors of the machine hall were closed.

In the second work process, the previously sawn strips (L: $20 \mathrm{~cm}$; W: $2 \mathrm{~cm}$ ) of pitchCFRP were subjected to tensile testing. The tensile testing machine was located within a separate laboratory room (L: $16 \mathrm{~m}, \mathrm{~W}: 11 \mathrm{~m}, \mathrm{H}: 4.6 \mathrm{~m}$, $810 \mathrm{~m}^{3}$ ) with a fresh air supply. During the measurements, all doors and windows were closed.

\section{Abrasion Experiments}

Abrasion experiments were performed with two different CFRP composites in a sealed test chamber, designed to host potentially hazardous abrasion dusts and to provide low particle background concentrations. It consisted of a stainless steel housing $\left(50 \mathrm{~cm} \times 50 \mathrm{~cm} \times 40 \mathrm{~cm}, 0.1 \mathrm{~m}^{3}\right)$ with a detachable poly (methyl methacrylate) front window. Photographs of the setup can be seen in Fig. 1.

For the experiments, the CFRP test specimens described in the Materials section were placed inside the test chamber and fixed to the bottom plate. A milling head placed directly above the specimen was connected via a shaft to a lowerable electrical drill (Metabo SBE 900 Impuls) that was mounted outside of the test chamber. The drilling shaft opening into the chamber was sealed by a rotary feedthrough and a rubber sleeve. An open-faced filter holder (asbestos cassette, SKC Inc., Eighty Four, PA, USA) equipped with a gold-coated track-etched membrane filter (200 nm nominal pore diameter, $25 \mathrm{~mm}$ filter diameter, APC GmbH, Eschborn,
Germany) was positioned in the test chamber at a distance of about $10 \mathrm{~cm}$ from the CFRP specimen and connected to a pulsation-free pump outside of the test chamber. The particle number concentration was monitored at a distance of about $10 \mathrm{~cm}$ with a CPC connected by a measure lance from the outside. Before processing, the test chamber was closed and flushed with particle-free compressed air at $20 \mathrm{~L} \mathrm{~min}^{-1}$ until the particle number concentration was below $5 \mathrm{\#} \mathrm{cm}^{-3}$. The outlet air was filtered with a HEPA (H14) filter. With reducing the compressed air supply to $1 \mathrm{~L} \min ^{-1}$ an air exchange rate of $0.6 \mathrm{~h}^{-1}$ was obtained. Subsequently the milling head, operating at $400 \mathrm{rpm}$, was lowered manually onto the specimen for about 20 seconds and then lifted up again for a few seconds to prevent heating of the sample. This milling process was repeated several times within the next hour. Aerosol sampling was performed during the process and the decay phase for a total duration of $3 \mathrm{~h}$ at $4 \mathrm{~L} \mathrm{~min}^{-1}$. Sedimented dust samples of abraded material were taken from inside the chamber for SEM analysis after experiment.

\section{SEM Analysis of Bulk Samples}

Filter samples collected during the orienting workplace measurements were imaged with a scanning electron microscope (Hitachi SU8030, Hitachi High-Technologies Europe $\mathrm{GmbH}$, Krefeld, Germany) at a magnification of $\times 2,000$, an accelerating voltage of $3 \mathrm{kV}$ and a working distance of ca. $7 \mathrm{~mm}$. For each sample, images with a standard resolution of $5,120 \times 3,840$ pixels were taken at 20 to 72 (depending on the sampling parameters to achieve the correlated volume) randomly chosen filter positions, resulting in an image resolution of $12.4 \mathrm{~nm} /$ pixel. A total imaged filter area of $0.060 \mathrm{~mm}^{2}$ to $0.218 \mathrm{~mm}^{2}$ was used for counting fibers and the determination of airborne fiber number concentrations (compare Table 1 and section "Strategy for the workplace measurement").

Bulk air samples and sedimented dust samples from the test chamber formed during abrasion experiments with pitchCFRP and panCFRP were characterized morphologically.
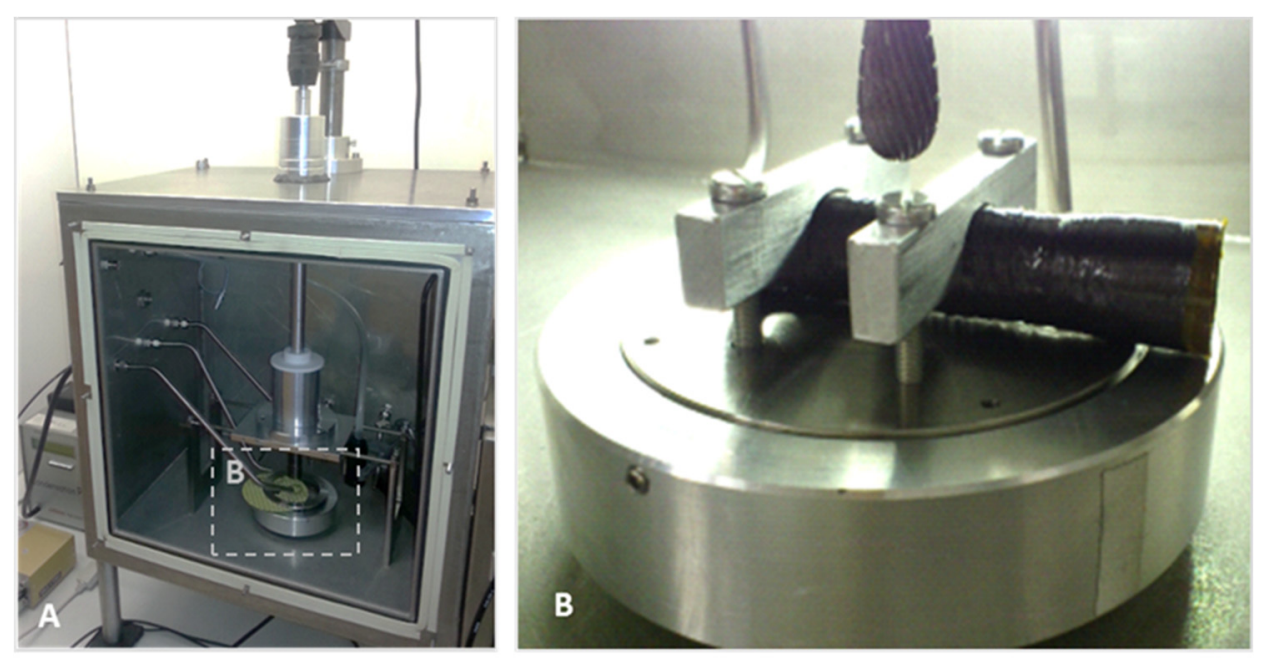

Fig. 1. Experimental setup of the (A) abrasion chamber and (B) a close up of the machining stage. 
The filters were imaged with SEM at a magnification of $\times 1,000$ or $\times 2,000$, an accelerating voltage of $3 \mathrm{kV}$ and a working distance of ca. $8 \mathrm{~mm}$ at randomly chosen filter positions. A total of at least 500 particles were counted and categorized into the following three morphological classes: Non-fibrous low aspect ratio (LAR) particles with $\mathrm{L} / \mathrm{D}<3$, fibrous high aspect ratio (HAR) particles with $\mathrm{L} / \mathrm{D} \geq 3$ and HAR particles with dimensions according to the WHOfiber geometry. The lengths and diameters were determined for all HAR-particles and WHO-fibers found.

Sedimented dust samples were dispersed in isopropanol $\left(0,015 \mu \mathrm{g} \mathrm{mL} \mathrm{m}^{-1}\right.$, without ultrasonic or another kind of energy input). The dispersion was dripped onto a polished silicon wafer for subsequent SEM analysis.

\section{RESULTS}

\section{Background Measurement at the Workplace}

Prior to mechanical processing of the pitchCFRP material, the background $(\mathrm{BG})$ particle concentration was measured overnight by means of CPC and OPC. Time series data is presented in Fig. S1 of the supporting information. Likewise, filter samples were collected overnight in the machine hall close to the band saw as well as in the laboratory close to the tensile testing machine to quantify and characterize aerosol particles by SEM. In the machine hall, the background concentration measured with $\mathrm{CPC}$ and $\mathrm{OPC}$ varied from $2000 \# \mathrm{~cm}^{-3}$ to $8000 \# \mathrm{~cm}^{-3}$ and $40 \# \mathrm{~cm}^{-3}$ to $390 \# \mathrm{~cm}^{-3}$, respectively. SEM analysis of the background filter samples revealed that fibers concentrations stayed below an upper interval limit of the $95 \%$ confidence interval of about 4000 WHO-fiber $\mathrm{m}^{-3}$ (cf. Table 1).

\section{Particle Release during Sawing}

The temporal development of particle number concentrations is shown in Figs. 2(A) and 2(B) for CPC and OPC data, respectively. According to CPC data, no substantial increase in the particle number concentration was observed during the sawing process, except some spikes that are still in the range of the background concentration. Immediately after the process and while using the vacuum cleaner, the concentration peaked to a range of about $40000 \mathrm{H} \mathrm{cm}^{-3}$. Within the next $30 \mathrm{~min}$ the concentration decayed back to background levels (same order of
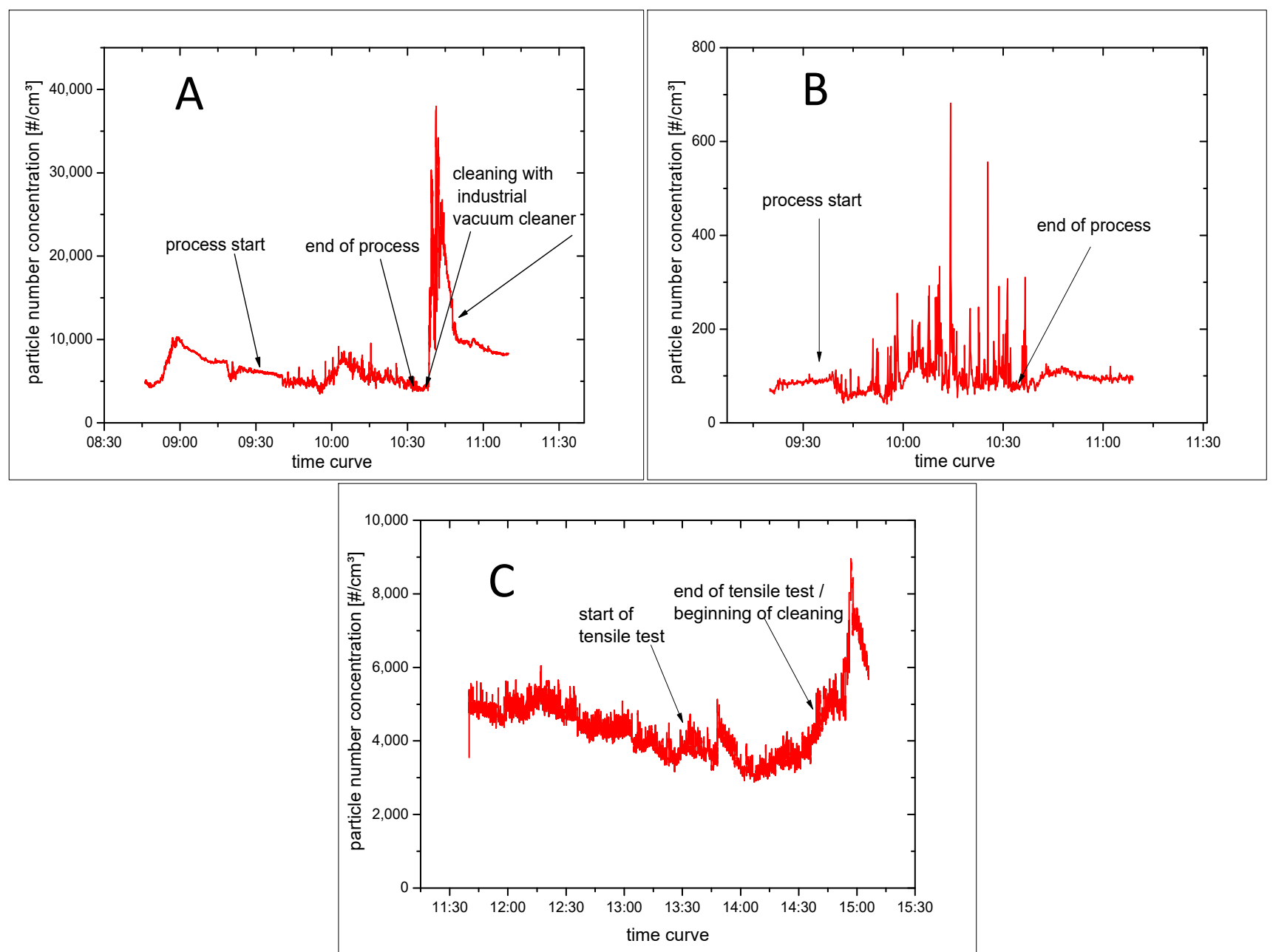

Fig. 2. Time curve of particle number concentration, as measured by (A) CPC and (B) OPC during the monitoring of sawing process and (C) CPC measurements during tensile testing. Important events like the process beginning or end are marked. 
magnitude) were reached again. For the microscale particle range, the OPC measured a number of spikes considerately higher than the background concentration during the process. They exceeded the background concentration by a

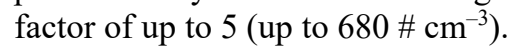

SEM images of the filter close to both processes (NF) showed a large number of differently shaped CF fragments, cf. Fig. 3. Many fragments found exhibited microscale and sub-microscale dimensions. In some cases, the fragments were agglomerated to larger clusters. Few of the CF fragments found on the filters had maintained the original fiber diameter of $10 \mu \mathrm{m}$. Notably is the high amount of fibrous fragments with aspect ratios $\geq 3$, many, 116 for instance in the example of sawing (cf. Table1), of them fit in the WHO definition of respirable and potentially harmful fibers.

Quantification of the NF bulk air samples by SEM resulted in a process-related number concentration of about 830,000 WHO-fiber $\mathrm{m}^{-3}$ for sawing at a distance of $15 \mathrm{~cm}$ from the saw blade (compare Table 1). Again, it should be noted that these concentrations are not to be interpreted as shift-based workplace concentrations due to deviating sampling time, airflow and sampling position. The evaluation of the filter in the FF of the saw likewise revealed a high concentration of 33,000 WHO-fiber $\mathrm{m}^{-3}$ at a distance of approximately $3 \mathrm{~m}$ from the saw, showing that potentially harmful fibers were distributed inside the hall.

\section{Particle Release during the Tensile Testing}

Due to technical problems with the instrument, no data was recorded by the OPC during tensile testing. The temporal development of particle number concentrations as measured with CPC is shown in Fig. 2(C). No substantial increase compared to the background in the particle number concentration correlated to the tensile testing was observed.

SEM analysis of the filter close to the test specimen showed the release of CF fragments in different shapes, comparable to those found during sawing. By evaluation of SEM images, a process-related WHO-fiber concentration of 425,000 WHO-fibers $\mathrm{m}^{-3}$ was determined during the tests at a distance of $10 \mathrm{~cm}$. However, the sawn specimens were not thoroughly cleaned prior to the tensile test. Thus, a carryover effect of fragments from the sawing process attaching to the test specimen cannot be ruled out. This could have led to an overestimation of the number of fiber fragments emitted at the tensile testing unit. However, we did not want to change work flow of this specific workplace to have a correct assessment of the situation. In the far field at a distance of $3 \mathrm{~m}$, the fiber concentration was below the detection limit of about 7,000 WHO-fiber $\mathrm{m}^{-3}$.

\section{Abrasion Experiments}

After SEM analysis of the bulk air samples of the abrasion experiments, all particles and fibers in the analyzed filter area were counted and classified into non-fibrous LAR and fibrous HAR particles as well as WHO-fibers and agglomerates, further called WHO particles. As shown in Fig. 4(A), abrasion of pitchCFRP released a considerably higher percentage of fibrous fragments than panCFRP. In this experiment, the proportion of particles with WHOdimensions from pitchCFRP was found to be eight times larger than from panCFRP. For fibrous HAR particles it was 6 times higher, but for non-fibrous LAR objects panCFRP emitted nearly twice the amount as pitchCFRP. For the studied pitch- and PAN-based carbon fiber types, machining of pitchCRFP is therefore expected to release substantially more potentially hazardous fibers than of panCFRP.

Figs. 4(B) and 4(C) show examples of the WHO particles found after abrasion of the two composite materials. It must be noted that the identified fragments with WHO-fiber geometry from panCFRP abrasion appear to be agglomerates composed of resin matrix and fiber fragments that may only be loosely attached to each other. The individual constituents of these agglomerates do not exhibit WHO dimensions. All WHO-objects found after panCFRP abrasion are shown in Fig. S2 of the supporting information.

The WHO-fiber fragments from pitchCFRP abrasion were mostly fragments of the pitchCF with no or hardly any matrix attached.

Fig. 5 displays the diameter versus length distributions of WHO-fiber and HAR particles found during the analysis of bulk air samples of the abrasion experiments. This is to some extent another visualize the HAR and WHO

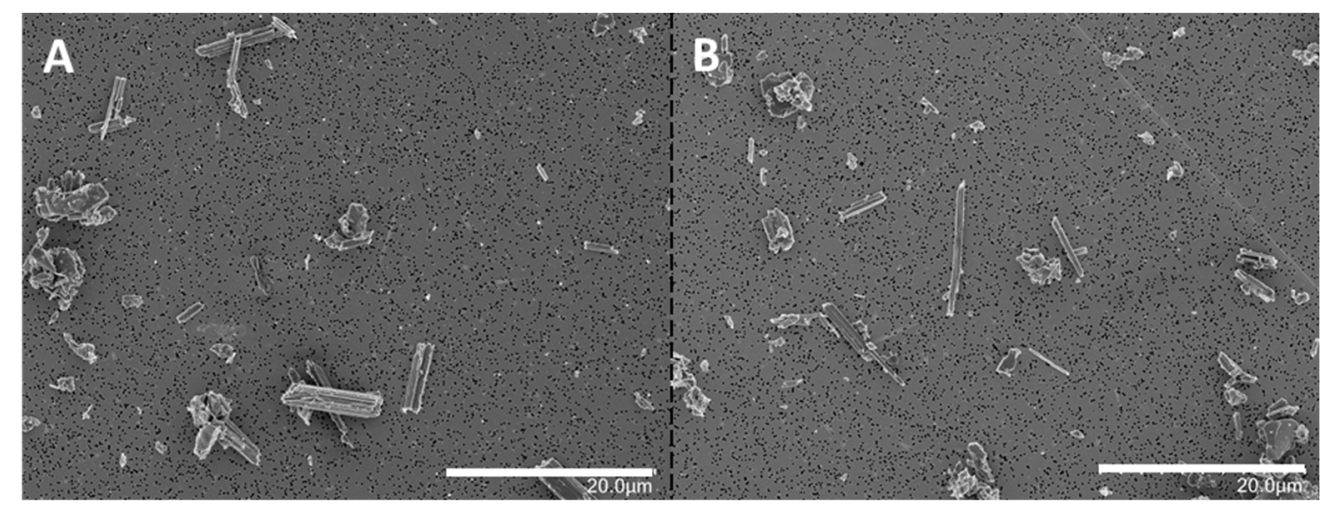

Fig. 3. Exemplary SEM images of bulk air samples collected during (A) the sawing process and (B) the tensile testing. The images were used to determine the process-related number concentrations of WHO-fibers. Fiber fragments of different shapes and dimensions can be seen. 

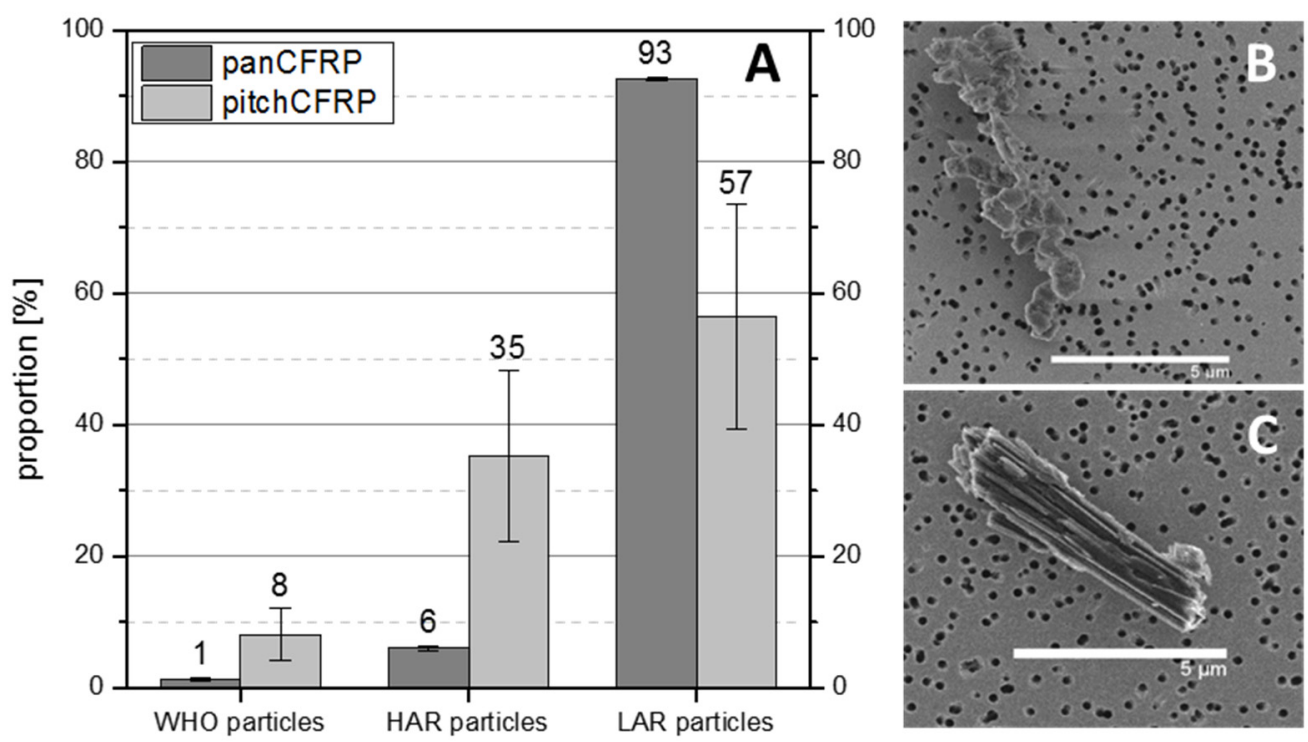

Fig. 4. Proportions of classified particles collected on filters during abrasion experiments of (A) panCFRP and pitchCFRP; WHO objects of (B) panCFRP and (C) pitchCFRP.
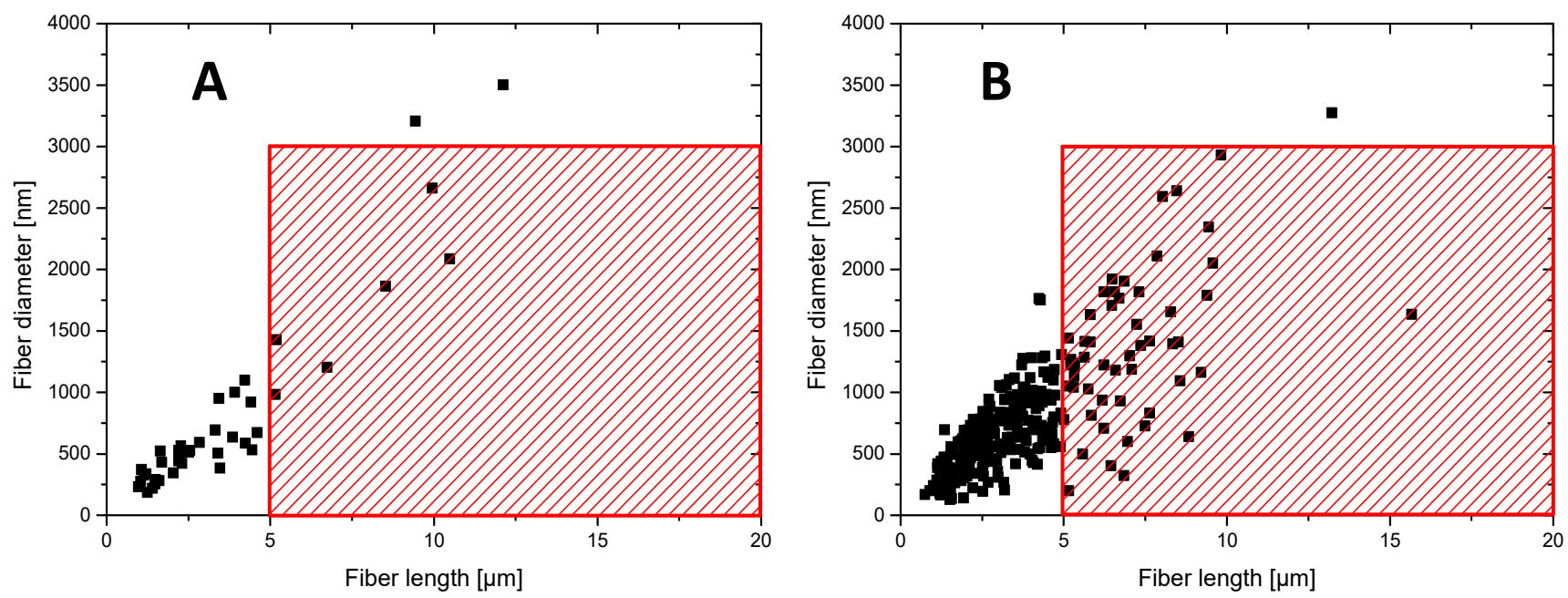

Fig. 5. Distribution of fiber diameter over fiber length for all WHO- and HAR-objects found during the analysis of the bulk air samples of the abrasion experiments of (A) panCFRP and (B) pitchCFRP. The hatched area marks the WHO-fiber fraction.

data underlying the histograms in Fig. 4(A). The difference in data point density shows that the studied pitchCF emitted considerably more fiber fragments, especially such with WHO-dimensions, than the studied panCF, which has emitted mostly fragments of the LAR category, not shown in this diagram. Furthermore, Fig. 5 shows that from both CF materials fragments with diameters smaller than the original fiber diameter were generated. This is most notably for pitchCFRP, where even WHO-fibers with diameters as low as about $200 \mathrm{~nm}$ have been found.

Samples of sedimented abraded material were collected both for panCFRP and pitchCFRP following the experiments to characterize and compare the respective particle morphologies. In Fig. 6 SEM images of the material samples reveal substantial differences between pitchCFRP and panCFRP debris especially at fractured fiber ends: Micrographs A and B show a fractured fiber end mostly resin-free in top view. The panCF has a cleaner, shaper edge, whereas the pitchCF exhibits a more fragmented, ragged edge. The surface of the panCF is smooth, while the surface of the pitchCF shows many ridges. The difference in fiber surface structure is believed to be related to the internal microstructure of the fibers, which can be seen in micrographs $\mathrm{C}$ and $\mathrm{D}$. A more granular structure is observable for the studied panCF. Thin fibrils and the typical layer like structure of partially crystalline graphitic materials characterize the studied pitchCF. The last series of micrographs (E and F) show a small overview of fracture debris. Granular, predominantly non-fibrous fragments can be seen for the panCFRP. For the pitchCFRP, 


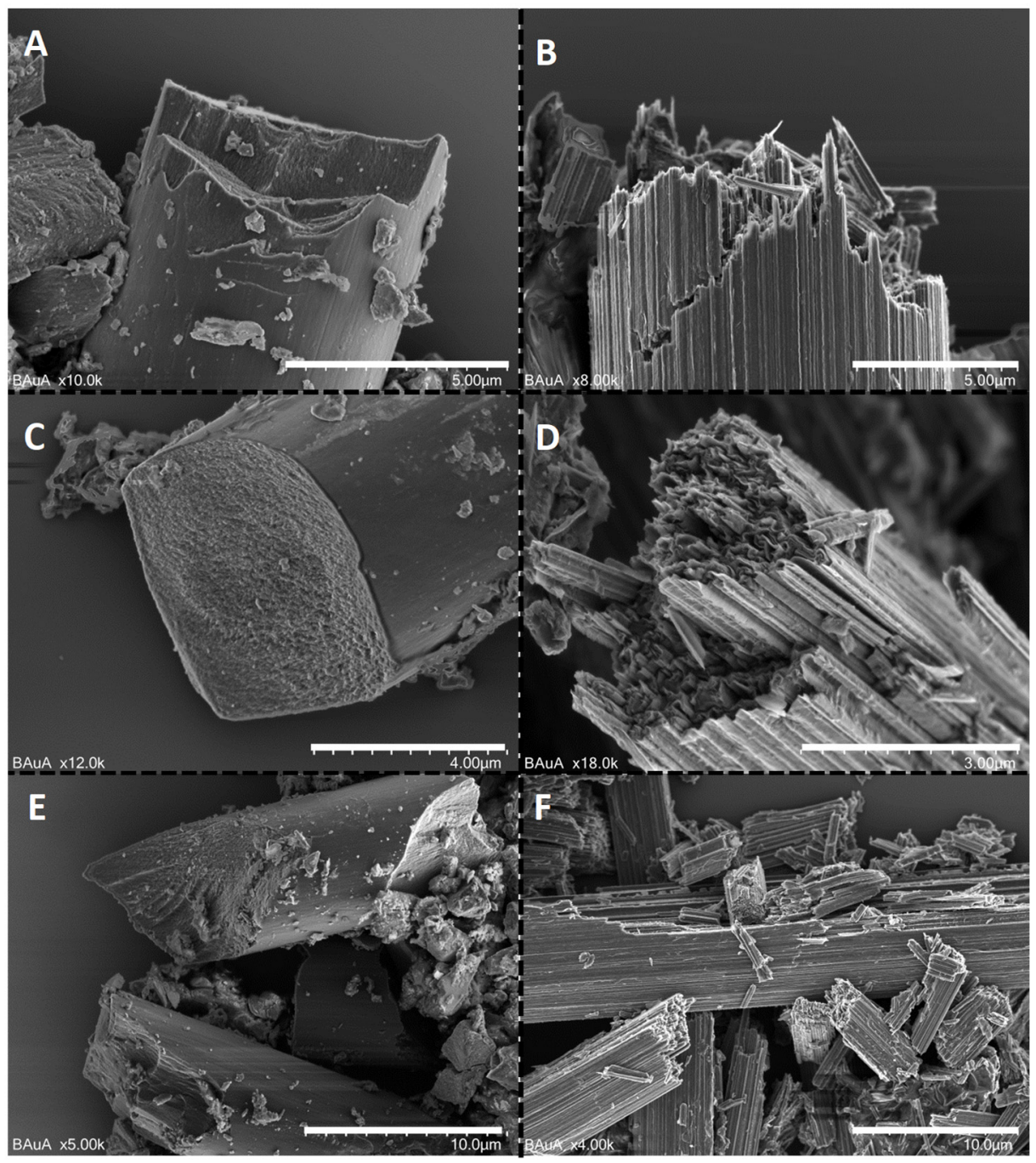

Fig. 6. Edge of the fracture of $\mathrm{CF}$ for (A) panCF and (B) pitchCF; Internal microstructure of (C) panCF and (D) pitchCF; $\mathrm{CF}$ fragments generated in the abrasion experiments (E) panCFRP let assume fracture perpendicular to the fiber axis, whereas $(\mathrm{F})$ pitchCFRPshow signs of splitting along the fiber axis.

however, many fibrous fragments with diameters smaller than the original fiber diameter are notable. The structure of pitchCF appears to be much more brittle and to favor spall fracture and thus the formation of fibrous fragments. Even more so in some pictures a splicing of the pitchCF into its fibrils and a general splitting along the fiber axis can be seen; cf. Fig. S3 of the supporting information.

\section{DISCUSSION}

The orienting workplace measurements carried out in this study show two major findings that suggest a reviewing of the occupational hygiene requirements for specific types of carbon fibers and derived composites.

On one hand the CPC data indicated - at a first glance that only a low concentration of respirable dust (dust that can penetrate beyond the terminal bronchioles into the gasexchange region of the lungs, aerodynamic diameter $<10 \mu \mathrm{m})$ was emitted during the mechanical processing. However, the calculated number concentrations of WHO- fibers based on the particles found on the collected filter samples are considerable. The sensitivity of the real-time measurement techniques used in this study was too low to detect the release of critically high fiber number concentrations. Even the observed maximum concentration of 830,000 WHO-fiber $\mathrm{m}^{-3}$ corresponds to only about 1 WHO-fiber $\mathrm{cm}^{-3}$. This is too low for detection with a $\mathrm{CPC}$, with regard to the observed workplace background concentration and the given measurement inaccuracy of the devices (Asbach et al., 2017). Moreover, most real-time reading devices cannot distinguish between particle, fibers and WHO-fibers. Since the fibers that have precipitated onto the filter are visual and tangible evidence of emitted fibers, one can only deduce that the optical light scattering measurement of fibers by devices calibrated to measure spherical particles must be inconclusive. Their at least 2 orders of magnitude too low sensitivity in combination with a lack of morphological information renders devices like OPC und CPC unsuitable for assessing risks related to alveolar fiber dust exposures. Such severe underestimation 
of the actual fiber number concentrations could lead to a false assessment of the safety of workplaces handling or processing fibers and fiber-containing materials.

On the other hand the high number of $\mathrm{CF}$ fragments with WHO-fiber geometry observed in this work during mechanical processing of the studied pitchCFRP in the near-field and far-field clearly deviate from the findings of previous studies that mainly focused on panCF and reported only harmlessly low concentrations or even no WHO-fibers (Mazumder et al., 1982; Boatman et al., 1988; Seibert, 1990; Deutsche Gesetzliche Unfallversicherung - Fachbereich Holz und Metall, 2014; Schlagenhauf et al., 2015). Our findings disprove the previous widely accepted hypothesis that all types of carbon fibers break in a glass-like, isotropic, non-fibrous manner, predominantly transversely to the fiber axis, and no considerable release of respirable fibrous fragments must be expected.

The highest concentration detected in our study, as mentioned above, was during sawing with about 830,000 WHO-fiber $\mathrm{m}^{-3}$. The fiber concentration measured during the sawing in the far-field shows that the released particles and fibers migrated through the hall. Due to the high number of released fibers, even the concentration in the FF at $3 \mathrm{~m}$ distance from the saw was in a potentially health affecting range of 33,000 $\mathrm{WHO}$-fiber $\mathrm{m}^{-3}$. The orienting workplace measurement carried out and the investigated intermittent processes do not reflect a workplace measurement of an eight-hour work-shift. To pin down these numbers in relation to the German Asbestos OEL of $10,000 \mathrm{~F} \mathrm{~m}^{-3}$ or the limit for inorganic fibers without sufficient toxicological data of $50,000 \mathrm{~F} \mathrm{~m}^{-3}$, one can estimate an eight-hour shift by adding up the found concentration for a 90-minute process with a concentration of 0 for the remaining 6.5 hours, which still leads to a concentration of $155,625 \mathrm{~F} \mathrm{~m}^{-3}$. During the tensile testing, the number of released fibers was lower, but still in the range of 425,000 WHO-fiber $\mathrm{m}^{-3}$ or 79,688 WHO-fiber $\mathrm{m}^{-3}$ estimated for a whole shift. Both processes exceeded possibly relevant OELs, which has to raise red flags regarding working with pitch-based CF.

However, the sawn specimens were not cleaned before the tensile test, so that a carryover of fragments from the sawing process cannot be ruled out. This could have led to an overestimation of the number of fiber fragments emitted on the tensile testing unit.

The high airborne fiber concentrations found at workplaces motivated to further investigate pitchCFRP in abrasion processes under controlled laboratory conditions, with the focus on comparing the released particles and abraded material morphologies to that of panCFRP. We wanted to find out, whether the high concentration for pitchCFRP can be confirmed in the laboratory. The obtained results clearly display a difference in the fracture behavior for the two studied CF. The panCF predominantly broke into pieces of different length but with the same diameter as the original fiber, which indicates a fracture perpendicular to the fiber axis. The pitchCF broke into pieces of different lengths and diameters with many of them having diameters smaller than the original one, which indicates fracturing along the fiber axis. Moreover, high resolution SEM images reveal a crystallite, fibril-like microstructure of the studied pitchCF that must have resulted from high-temperature graphitization of mesophase pitch that was pre-oriented on molecular level by stretching of the precursor fiber (Huang, 2009). The morphology of such partially crystalline graphitic domains is believed to determine the smallest possible fragment size that could even reach down to WHO-fibers with diameters in the nanometer range. In this study we found WHO-fibers, released from pitchCF, with diameters as low as about $200 \mathrm{~nm}$. Such low dimensions could prove to be challenging to detect during exposure assessment analyses, in particularly for recycling processes of polymer- or concrete-based CF composites, where a lot of micro or even millimeter sized granular dust particles are released and dominate the filter samples.

We also found 8 times more WHO-objects and 6 times more HAR-particles on the analyzed filter samples for abraded pitchCFRP compared to panCFRP. This supports the assumption of a more brittle microstructure of the pitchCF. However, it should be mentioned again that the identified particles with WHO-fiber geometry of the panCFRP abrasion dust were predominantly agglomerates consisting of resin matrix and granular-shaped fiber fragments that appear to be loosely attached to each other. The individual components of these agglomerates have no WHO-fiber dimensions. It is not in the scope of the present study to decide or discuss a distinction in toxicological potency of such differently built up WHO-fiber-shaped respirable objects.

As mentioned earlier, the carbon fiber market is currently essentially split into PAN- and pitch-based CFs. Depending on the process control, stretching, carbonization and graphitization processes, including temperature and duration; they can be transformed into $\mathrm{CF}$ products with a wide range of physical and surface-chemical properties. These fiber products cover a broad and partially overlapping property spectrum with regard to Young's modulus, tensile strength, elongation at break as well as thermal and electrical conductivity.

The microstructure, which we believe significantly influences the fracture behavior of such fibers has been reported to be highly diverse (Naito et al., 2009; Naito et al., 2017) and is influenced by precursor, spinning, stretching, oxidation, carbonization and graphitization process details. As a general trend, crystallites grow bigger and more aligned at higher process temperatures and holding durations (Qin et al., 2012). Also handling and treatment of the precursor material can greatly influence fiber microstructure and mechanical properties. The tacticity (atactic, isotactic or snydiotactic) of the molecular chains of PAN defines the effectivity of the molecular chain packing (free volume) and with that the resulting density and crystallinity of the fabricated fibers (Shen et al., 2018). For pitchCF isotropic, anisotropic and mesophase pitch precursors are being used, with the latter as the most common. All three precursors can result in very different microstructures (Naito et al., 2009; Naito et al., 2017). A difference in the microstructure was also found by our SEM analyses for the here studied CF types. The pitchCF 
used in the present study exhibited higher thermal conductivity, lower elongation at break and higher material density compared to the studied panCF. These are indications of a higher crystallinity of the pitchCF, which could account for the observed fracture behavior.

Carbon fibers are generally categorized according to their tensile strength (tenacity), ranging from 2,000 to $6,000 \mathrm{MPa}$ for standard and ultra-high tenacity $\mathrm{CF}$, and Young's modulus, ranging from 200 to $800 \mathrm{GPa}$ for high and ultra-high modulus CF. Currently, only pitch-based CFs are said to reach ultra-high modulus values above $400 \mathrm{GPa}$. Elongation-to-break values significantly below $0.8 \%$ are only reached by ultra-high modulus fibers. However, $\mathrm{CF}$ in the high tenacity and high modulus range can be synthesized from both main precursors, so that there are also fibers of the respective other type, with comparable properties. Further investigations are necessary to elucidate the role of the fiber microstructure and to clarify to what extent our findings of high respirable fiber dust release may likewise be expected for other pitch- or PAN-based carbon fiber types.

\section{CONCLUSION}

In this study we assessed workplace atmospheres in the near- and far-field during sawing and tensile testing of carbon fiber reinforced polymer composites. These dust emission studies were accompanied by abrasion experiments in a laboratory setup. Comprehensive morphological analyses of airborne respirable dust on sampled filters revealed that high concentrations of WHO-fibers were released during mechanical processing of polymer composites that were reinforced with pitch-based carbon fibers. Despite their only orienting character, the findings of our workplace measurements should be considered as highly relevant for realizing, assessing and managing potential health risks related to processing, handling, machining and recycling of CFRP. To the knowledge of the authors, the observed excessive fiber dust formation and release propensity of the pitch-based carbon fibers has not been noticed or considered irrelevant in the literature to date. Due to the chemical inertness of graphite, a high biopersistence of graphitic debris particles and fibers in lung tissue must be assumed. According to the fiber pathogenicity paradigm (Pott and Friedrichs, 1972; Stanton and Wrench, 1972), inhalation of respirable biopersistent fibers, as were released from the studied pitch-based carbon fibers, can be associated with a potential health risk, including lung cancer and mesothelioma.

The considerably different propensities of the studied pitch- and PAN-based carbon fibers to form respirable fragments upon disintegration observed during laboratory experiments show that further research is necessary. As long as the influence of the microstructure of pitch-based and PAN-based carbon fibers on their fracture behavior has not been systematically investigated and fundamentally understood, exposure measurements and increased levels of occupational safety appear mandatory for all work tasks involving high modulus carbon fibers and in particular highly thermal conductive carbon fiber materials. Based on the less critical fracture behavior of the PAN-based carbon fibers investigated in the present and previous studies, it should not be conclude that an equally uncritical behavior of pitch-based carbon fiber, as has hitherto been the case, can be assumed. For every carbon fiber type, a dedicated examination of its fracture morphology must be undertaken, including different composite matrix materials and disintegration scenarios.

Until the questions and concerns raised in this study, which are also arising within the carbon fiber community, are conclusively answered, we strongly advice to accompany any handling of pitch-based carbon fiber and pitchCF containing products to take appropriate precautionary measures to ensure occupational safety.

\section{SUPPLEMENTARY MATERIAL}

Supplementary data associated with this article can be found in the online version at http://www.aaqr.org.

\section{REFERENCES}

AGS (2016). Trgs 905 Verzeichnis Krebserzeugender, Keimzellmutagener Oder Reproduktionstoxischer Stoffe, In 19, Gemeinsames Ministerialblatt.

Asbach, C., Alexander, C., Clavaguera, S., Dahmann, D., Dozol, H., Faure, B., Fierz, M., Fontana, L., Iavicoli, I., Kaminski, H., MacCalman, L., Meyer-Plath, A., Simonow, B., van Tongeren, M. and Todea, A.M. (2017). Review of measurement techniques and methods for assessing personal exposure to airborne nanomaterials in workplaces. Sci. Total Environ. 603-604: 793-806.

Bello, D., Wardle, B.L., Yamamoto, N., Guzman deVilloria, R., Garcia, E.J., Hart, A.J., Ahn, K., Ellenbecker, M.J. and Hallock, M. (2009). Exposure to nanoscale particles and fibers during machining of hybrid advanced composites containing carbon nanotubes. J. Nanopart. Res. 11: 231-249.

Bello, D., Wardle, B.L., Zhang, J., Yamamoto, N., Santeufemio, C., Hallock, M. and Virji, M.A. (2010). Characterization of exposures to nanoscale particles and fibers during solid core drilling of hybrid carbon nanotube advanced composites. Int. J. Occup. Environ. Health 16: 434-450.

Boatman, E.S., Covert, D., Kalman, D., Luchtel, D. and Omenn, G.S. (1988). Physical, morphological, and chemical studies of dusts derived from the machining of composite-epoxy materials. Environ. Res. 45: 242-255.

Deutsche Gesetzliche Unfallversicherung - Fachbereich Holz und Metall (2014). Dguv-Information Fb Hm-074 - Bearbeitung Von Cfk-Materialien - Orientierungshilfe Für Schutzmaßnahmen, pp. 1-5.

Donaldson, K., Murphy, F.A., Duffin, R. and Poland, C.A. (2010). Asbestos, carbon nanotubes and the pleural mesothelium: A review of the hypothesis regarding the role of long fibre retention in the parietal pleura, inflammation and mesothelioma. Part. Fibre Toxicol. 7: $1-17$. 
Eibl, S., Reiner, D. and Lehnert, M. (2014). Gefährdung durch lungengängige Faserfragmente nach dem Abbrand Kohlenstofffaser verstärkter Kunststoffe. Gefahrstoffe Reinhalt. Luft 74: 285-286.

Eibl, S. (2017). Potential for the formation of respirable fibers in carbon fiber reinforced plastic materials after combustion. Fire Mater. 41: 808-816.

European Union (2008). Classification, Labelling and Packaging of Substances and Mixtures, In Regulation (EC) No 1272/2008, European Union (Ed.), Official Journal of the European Union.

Gandhi, S., Lyon, R. and Speitel, L. (1999). Potential health hazards from burning aircraft composites. J. Fire Sci. 17: 20-41.

Gieseke, J., Reif, R.R. and Schmidt, E. (1984). Characterization of carbon fiber emissions from current and projected activities for the manufacture and disposal of carbon fiber products. US Environmental Protection Agency, Washington, D.C.

Henry, W., Malton, M.C. and Schmidt, E.W. (1982). Method for measuring carbon fiber emissions from stationery sources. US Environmental Protection Agency, Washington, D.C.

Holt, P.F. and Horne, M. (1978). Dust from carbon fibre. Environ. Res. 17: 276-283.

Huang, X. (2009). Fabrication and Properties of carbon fibers. Materials 2: 2369-2403.

Industry Experts (2018). Carbon Fibers \& Carbon Fiber Reinforced Plastics (CFRP) - A global market overview. Industry Experts, India.

Mazumder, M.K., Chang, R.J. and Bond, R.L. (1982). Aerodynamic and morphological properties of carbonfiber aerosols. Aerosol Sci. Technol. 1: 427-440.

Naito, K., Tanaka, Y., Yang, J.M. and Kagawa, Y. (2009). Flexural properties of pan- and pitch-based carbon fibers. J. Am. Ceram. Soc. 92: 186-192.

Naito, K., Tanaka, Y. and Yang, J.M. (2017). Transverse compressive properties of polyacrylonitrile (PAN)based and pitch-based single carbon fibers. Carbon 118: 168-183.

Plitzko, S., Meyer-Plath, A., Dziurowitz, N., Simonow, B., Steinle, P. and Mattenklott, M. (2018a). Messung nanound mikroskaliger faserförmiger Materialien an Arbeitsplätzen (Teil 1). Gefahrstoffe - Reinhalt. Luft 78: 187-192.

Plitzko, S., Meyer-Plath, A., Dziurowitz, N., Simonow, B., Steinle, P. and Mattenklott, M. (2018b). Messung nanound mikroskaliger faserförmiger Materialien an Arbeitsplätzen (Teil 2). Gefahrstoffe - Reinhalt. Luft 78: 251-256.

Pott, F. and Friedrichs, K.H. (1972). Tumoren der Ratte nach i.p.-Injektion faserförmiger Stäube. Sci. Nat. 59: 318.

Qin, X., Lu, Y., Xiao, H., Wen, Y. and Yu, T. (2012). A comparison of the effect of graphitization on microstructures and properties of polyacrylonitrile and mesophase pitch-based carbon fibers. Carbon 50: 44594469.

Rödelsperger, K. (2004). Extrapolation of the carcinogenic potency of fibers from rats to humans. Inhalation Toxicol. 16: 801-807.

Schlagenhauf, L., Kuo, Y.Y., Michel, S., Terrasi, G. and Wang, J. (2015). Exposure assessment of a high-energy tensile test with large carbon fiber reinforced polymer cables. J. Occup. Environ. Hyg. 12: D178-183.

SCOEL/SUM/88 (March 2012). Recommendation from the Scientific Committee on Occupational Exposure Limits for Man Made-Mineral Fibres (Mmmf) with No Indication for Carcinogenicity and Not Specified Elsewhere.

Seibert, J.F. (1990). Composite fiber hazards. AF occupational and environmental health laboratory, Texas, U.S.A.

Shen, T., Li, C., Haley, B., Desai, S. and Strachan, A. (2018). Crystalline and pseudo-crystalline phases of polyacrylonitrile from molecular dynamics: Implications for carbon fiber precursors. Polymer 155: 13-26.

Stanton, M.F. and Wrench, C. (1972). Mechanisms of mesothelioma induction with asbestos and fibrous glass. J. Natl. Cancer Inst. 48: 797-821.

VDI (2013). Vdi-Richtlinie 3492 - Messen Von Innenraumluftverunreinigungen - Messen Von Immissionen - Messen Anorganischer Faserförmiger Partikel - Rasterelektronenmikroskopisches Verfahren, Verein Deutscher Ingenieure, Düsseldorf.

Wang, J., Schlagenhauf, L. and Setyan, A. (2017). Transformation of the released asbestos, carbon fibers and carbon nanotubes from composite materials and the changes of their potential health impacts. $J$. Nanobiotechnology 15: 15.

Warheit, D.B., Hansen, J.F., Carakostas, M.C. and Hartsky, M.A. (1994). Acute inhalation toxicity studies in rats with a respirable-sized experimental carbon fibre: Pulmonary biochemical and cellular effects. Ann. Occup. Hyg. 38: 769-776.

Warheit, D.B., Hart, G.A., Hesterberg, T.W., Collins, J.J., Dyer, W.M., Swaen, G.M.H., Castranova, V., Soiefer, A.I. and Kennedy, G.L. (2001). Potential pulmonary effects of man-made organic fiber (MMOF) dusts. Crit. Rev. Toxicol. 31: 697-736.

WHO (1997). Determination of airborne fibre number concentrations: A recommended method, by phasecontrast optical microscopy (Membrane Filter Method), World Health Organization, Geneva.

Received for review, April 25, 2019 Revised, August 22, 2019 Accepted, August 24, 2019 